\title{
Low back pain disability and stay at work: contradiction or necessity?
}

\author{
Rosimeire Simprini Padula ${ }^{\mathrm{a}, \mathrm{b}^{*}}$, Rodrigo Luiz Carregaro ${ }^{\mathrm{c}}$, Bruna Melo ${ }^{\mathrm{a}}$, Cláudia Regina da Silva ${ }^{\mathrm{a}}$ and \\ Ana Beatriz Oliveira ${ }^{\mathrm{d}}$. \\ ${ }^{a}$ School of Physiotherapy, Universidade São Francisco Av. São Francisco de Assis, 218, Bragança Paulista, São \\ Paulo, Brazil \\ ${ }^{b}$ Masters in Physical Therapy Program, Universidade Cidade de São Paulo, R. Cesário Galeno, 448, São Paulo, \\ Brazil, \\ ${ }^{c}$ School of Physiotherapy, Universidade Federal de Mato Grosso do Sul, R. 7 de Setembro, 2008, Campo Grande, \\ Mato Grosso do Sul, Brazil. \\ ${ }^{d}$ Department of Physical Therapy, Universidade Federal de São Carlos, Via Washington Luis, Km 235, São \\ Carlos, SP.
}

\begin{abstract}
The incidence of occupational diseases in the population is high and factors such as long working hours, poor posture, psychological and physical stress can contribute to its development. Among work-related musculoskeletal disorders, back pain has a high prevalence. The aim of the present study was to quantify and characterize pain complaints and to identifyindividuals with low back pain, in order to assess the degree of disability. Participated 226 employees of an institution of higher education. They answered a general questionnaire about location and quantification of pain complaints visual analog scale for pain and the Quebec Disability Questionnaire. Of all the workers, 69.60\% had some type of musculoskeletal complaint; of those, $15.41 \%$ had low back pain. Considering workers who had back pain, $54.9 \%$ were female, $52.94 \%$ are under 30 years old and $43.14 \%$ between 1 and 5 years of work. As for the final score for the degree of disability, $41.17 \%$ had minimal disability and $37.25 \%$ moderate disability. The present study found large number of pain complaints and high prevalence of low back pain, resulting in individual's inability and difficulties in performing work activities.
\end{abstract}

Keywords: musculoskeletal disorders; ergonomic risk factors; occupational health;

\section{Introduction}

The incidence of occupational diseases in the population is high, and several factors contribute to its development such as long working hours, inadequate posture, psychological and physical stress. In this sense, one of the main complaints related to work is back pain, which have a high prevalence ${ }^{[5]}$ about $80 \%$ of workers at some point in life, and may cause temporary or permanent disability ${ }^{[6]}$.

Physical disability can be characterized as the loss or restriction of the individual's ability to perform one or more tasks, which compromises their performance in work and during activities of daily living ${ }^{[8]}$. Low back pain is one of the most disabling conditions that can lead to a deficiency of both functional performance and physical capacity, with possible effects on work activities, sports and social activities ${ }^{[7]}$. Some physical characteristics and risk factors that may be associated with low back pain, which includes flexibility, discrepancy in leg length, sacroiliac joint dysfunction, training intensity, muscle strength limitations ${ }^{[9]}$, central obesity and smoking ${ }^{[1]}$.

The objective of the present study was to identify the prevalence of back pain in workers at a university. A second objective was to characterize the degree of disability generated by back pain and its relationship with the workplace.

\footnotetext{
*Corresponding author. E-mail: rosipadula@gmail.com.
} 


\section{Methods}

The study had a cross-sectional design and occurred in two stages, the first consisting of a questionnaire with personal data; work time; characteristics of the activity; presence of pain or discomfort in the past year, pain location, type and intensity assessed by a visual analogue scale (VAS).

The questionnaires were given to all 275 workers employed in administrative, infrastructure and maintenance and cleaning sectors of a private institution of higher education, which should respond after one week.

About 226 (82.18\%) employees answered and who had a back pain episode was instructed to report the visual analog scale and the Quebec Disability Questionnaire ${ }^{[10]}$.

\subsection{Quebec disability scale}

The Quebec disability scale comprises 30 items, 20 items that assess the level of difficulty in performing activities of daily living, including working conditions, with a score from 0 to 5 according to the classification: (0) No difficulty (1) Minimum difficulty, (2) a little difficulty, (3) Moderate difficulty, (4) Very difficult, (5) Unable to perform, and other 10 items assess the level of capacity for work, with a score of 0 to 3 , getting classification able (0), probably able (1), probably unable (2) and unable (3).

The Disability Scale score of Quebec is obtained by summing the total responses of each individual, values score of the 30 items, divided by the maximum number of possible points on the scale that is 130, finally, the value must be multiplied by 100 .

Thus, the percentage has to be classified following the scale described by category of disability [10]: Inability minimal: from 0.0 to $20 \%, 21$ to $40 \%$ moderate disability; 41 to $50 \%$ severe disability; 61 to $80 \%$ disability total; from 81 to $100 \%$ means that the individual is bedridden or exaggerating their symptoms.

\subsection{Ethical aspects}

All subjects were informed about the objectives and procedures of the study and were invited to participate by signing an informed consent form that had been approved by the local ethics committee (Proc. $\mathrm{N}^{\mathrm{o}}$ 0021.0.142.000-10).

\subsection{Data analysis}

The Statistical Package for Social Sciences (SPSS) software version 13.0 was used for statistical analysis, and significance was set at 5\% $(P<0.05)$

Descriptive statistics and Pearson correlation test was applied.

\section{Results}

Of the 226 workers who answered the questionnaire, 106 were female $(46.90 \%)$ and 120 males $(53.10 \%)$, with age ranging from 17 to 62 years (mean age $35.23 \pm 11.01$ years). The average working time was $8.36 \pm 7.04$ years.

Reports of pain complaints of musculoskeletal origin occurred in $69.60 \%$ workers, which is demonstrated in Figure 1.

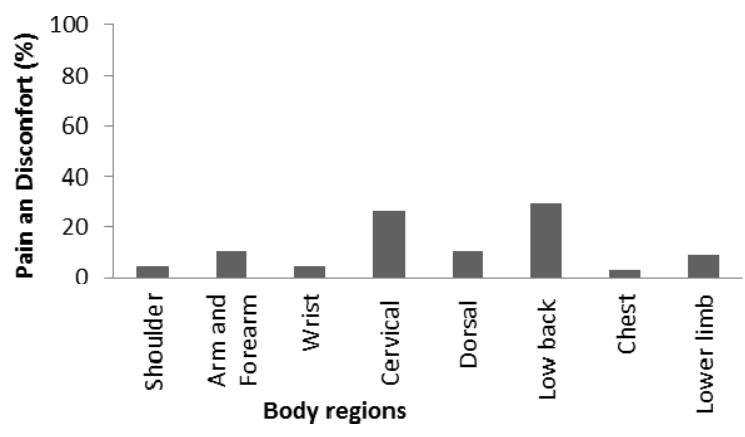

Figure 1. Body regions with musculoskeletal pain and discomfort

In respect to spine pain, $22.46 \%$ workers had an episode, $15.41 \%$ regarding at the low back Other body regions with pain complaints were the knee $(4.4 \%)$ and forearm $(3.96 \%)$.

Regarding the perception of pain, $38.21 \%$ and $27.38 \%$ reported a burning sensation and $17.19 \%$ reported throbbing.

In respect to work time, $39.65 \%$ are under 30 years and $38.76 \%$ have more than 10 years in the same function. In respect to gender, $45.10 \%$ are male and $54.9 \%$ are female, and $52.94 \%$ are under 30 years and $43.14 \%$ between 1 and 5 years of work.

In respect to pain intensity, $68.62 \%$ reported a moderate intensity (Figure 2 ). 


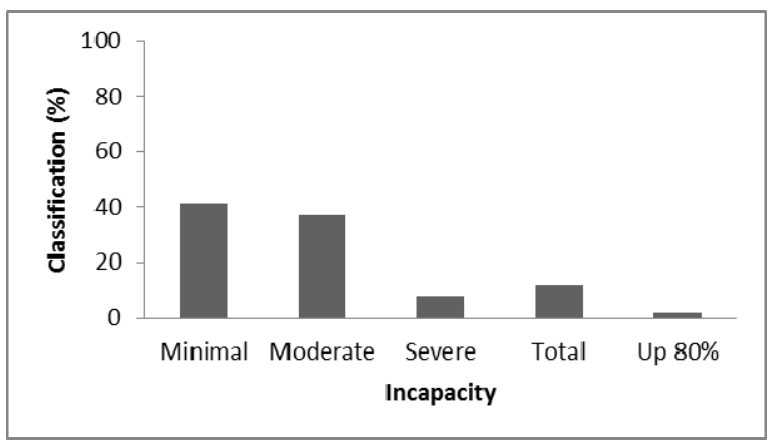

Figure 2. Classification of disorders according to the disability low back pain

The final score for the degree of disability demonstrated that $41.17 \%$ had a minimal disability and $37.25 \%$ presented a moderate disability.

There was no correlation between absence in work and pain intensity $(\mathrm{r}=-0.094 ; P>0.05)$. However, a moderate correlation between disability index and pain intensity were found $(\mathrm{r}=0.43, P=0,001)$.

\section{Discussion}

The presence of pain complaints and a high prevalence of low back pain can result in disability and difficulties during performance of work activities.

Considering all these symptoms, pain is the most notable. This may worsen gradually and progress to loss of function that can persist for variable periods of years or even become intractable ${ }^{[3]}$.

The low back pain is a symptom that in most cases heal in a few days. However, it is important to highlight that acute low back pain can become a chronic pain and be a recurrent health problem leading to disability. This fact demonstrates the importance of early preventive measures ${ }^{[4]}$.

Among the body regions affected by complaints of pain, the lumbar spine appears to be the most important one, followed by the cervical spine, hands, wrists and lower limbs ${ }^{[2]}$.

However, it is important to recognize that the presence of disability does not relieve workers from carrying out their occupational activities.

\section{References}

[1] Almeida ICGB, Sá KN, Silva MBA, Matos MA, Lessa I. Pre valência de dor lombar crônica na população da cidade de Salvador. Revista Brasileira de Ortopedia. 2008;43(3):96-102.

[2] Carregaro RL, Trelha CS, Mastelari HJZ. Distúrbios osteomusculares crônicos relacionados ao trabalho em fisioterapeutas: Revisão de Literatura. Fisioterapia e Pesquisa. 2006;13(1): 53-59.

[3] Coury HJCG, Moreira RFC, Dias NB. Efetividade do exercício físico em ambiente ocupacional para controle da dor cervical, lombar e do ombro: uma revisão sistemática. Revista Brasileira de Fisioterapia. 2009;13(6): 461-477.

[4] Heymans MW, Buuren SV, Knol DL, Anema JR, Mechelen WV, De Vet HCW. The Prognosis, of chronic low back pain is determined by changes in pain and disability in the initial period. The Spine Journal. 2010; 10 (10): 847-856.

Junior Helfenstein M, Goldenfum MA, Siena C. Lombalgia Ocupacional. Rev Assoc Med Bras. 2010; 56(5), 583592.

[5] Morris J, Watson PJ. Investigating decisions to absent from work with low back pain: A study combining patient and Gp factors. European Journal of Pain. 2011; 15 (3): 278-285.

[6] Ocarino JM, Gonçalves GGP, Vaz DV, Cabral AAV, Porto JV, Silva MT. Correlação entre um questionário de desempenho funcional e testes de capacidade física em indivíduos com lombalgia. Revista Brasileira de Fisioterapia. 2009; 13(4):343-349.

[7] World Health Organization (WHO). International classification of impairments, disabilities and handicaps: A manual of classification relating to the consequences of disease. In: Saúde Omd. Genebra; 1980.

[8] Santos KG, Silva MA, Pereira JS, Batista LA. A Prevalência de Lombalgia em praticantes de exercícios contra-resistência. Fisioterapia Brasil. 2004; 5(1):37-43.

[9] Kopec JA, Esdaile JM, Abrahamowicz M, Abenhaim L, Wood-Dauphinne S, Lamping DL,Williams JI. The Quebec Back Pain Disability Scale. Spine. 1995; 20 (3):341-352. 